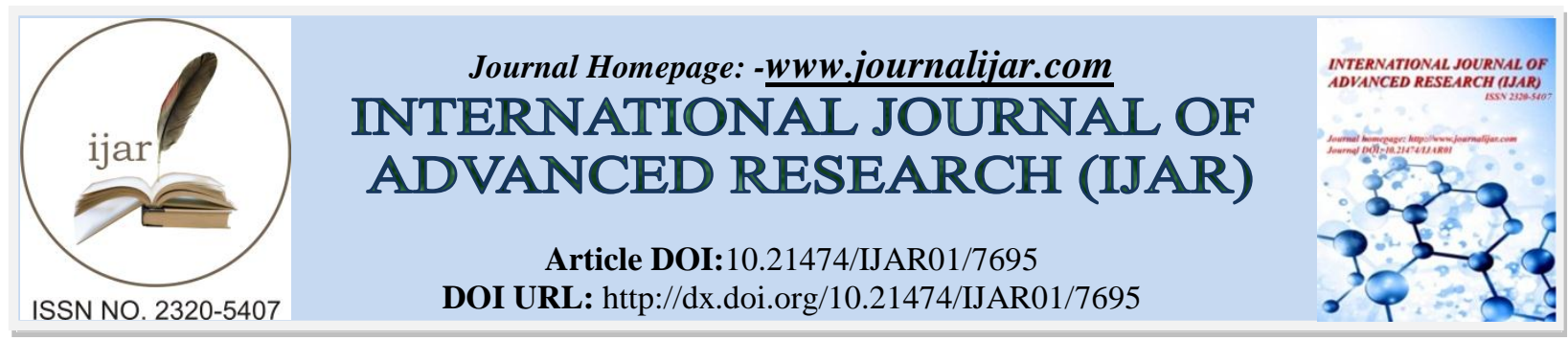

RESEARCH ARTICLE

\title{
"STEP UP" APPROACH IN MANAGEMENT OF ACUTE SEVERE PANCREATITIS - ANALYSIS OF FACTORS RESPONSIBLE FOR FAILURE OF PER CUTANEOUS DRAINAGE.
}

\section{Dr. Balram Goyal.}

Department of GI Surgery \& Liver Transplant Army Hospital (R\& R), Delhi Cantt - 110010.

\section{Manuscript Info}

Manuscript History

Received: 19 July 2018

Final Accepted: 25 August 2018

Published: September 2018

\section{Abstract}

Background: There is a paradigm shift towards minimally invasive approaches to manage local complications of acute pancreatitis specially infected necrosis. Step Up approach has been emerged during last decade to overcome the shortcomings of traditional open necrosectomy. Image-guided percutaneous drainage (PCD) is a minimally invasive intervention that helps "to bring out heat from fire".

It is currently not possible to predict that which subgroup of patients will need necrosectomy as a result of failure of percutaneous catheter drainage. This study was done to analyze the factors predicting failure of per cutaneous drainage.

Methods: This is a combined retro-prospective observational study included 42 patients with local complications of acute pancreatitis, managed at our centre during Jun 2010 to May 2017. We analyzed association between various demographic, hematological, biochemical, clinical and radiological variable predicting failure of per cutaneous drainage.

Results: All 42 patients included underwent image guided per cutaneous drainage initially. Catheter drainage was successful (survival without any other additional intervention) in 13 patients (30.95\%).

Copy Right, IJAR, 2018,. All rights reserved.

\section{Introduction:-}

Acute pancreatitis is a lethal disease with significant morbidity and mortality. The magnitude of acute pancreatitis is not well known. Its incidence varies from 30 to 80/100000 population and incidence has been reported to be increasing over the past two decades. In patients with infected necrosis traditional approach has been open necrosectomy, which itself associated high morbidity. Surgery in already compromised patient may deteriorate and often results in new onset organ failure and mortality. This lead to fall of favour for surgery and paradigm shift towards minimally invasive approaches to overcome the shortcomings of surgery. In 2010, the publication of the PANTER trial [1] popularized the "step-up" approach for management of infected necrosis.

\section{Study Design}

Total 42 patients with acute pancreatitis and signs of pancreatic necrosis who were treated during Jun 2010 to May 2017 enrolled and written and informed consent obtained. The patients with history of previous abdominal surgery and presented with complications like hollow viscus perforation and GI bleed were excluded. All relevant data of patient recorded and statistically analysed. 


\section{Intervention}

Patients having clinical and/or radiological evidence of infected necrosis, sterile pancreatic necrosis with deteriorating clinical condition, persisting organ failure, symptomatic acute fluid collection was managed with image guided per cutaneous drainage. Size and route (transperitoneal/ retroperitoneal) of PCD placement was decided by nature and location of necrosis. Response to PCD was measured either by improvement in clinical condition or by decreasing the size on USG/CECT abdomen which was done 48-72 hours after the procedure. Repositioning or additional catheter placement was done for patients who did not show any improvement in clinical condition or unsatisfactory drainage after 72 hours of primary catheter placement. Patients who failed to show any improvement following repositioning or additional catheter placement underwent necrosectomy.

\section{Outcome}

In this study 13 patients responded to PCD while failure group has 29 patients out of them 09 were died. Various predictors responsible for failure of percutaneous catheter drainage (PCD) in our study are male gender, low mean arterial pressure, high APACHE II score, number of organ failure prior to intervention, morphology and volume of necrosis on CECT abdomen before intervention.

\section{Statistical Analysis}

Statistical analysis was done by using descriptive and inferential statistics. P-value less than 0.05 considered as significant.

\section{Result:-}

A total of 42 patients were included in this study that required intervention as a result of local complications of acute pancreatitis. Total male and female patients included in this study were 22 and 20 respectively and mean age of

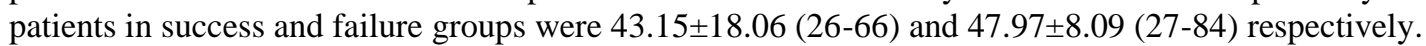

Gall stone was commonest cause of acute pancreatitis 19 patients (45.2\%), while alcohol was second most common cause responsible in 14 patients (33.3\%). Other less common causes were Idiopathic in 05 (11.9\%) patients, hypertriglyceridemia and pancreatic divisum were present in 02 patients each (4.8\%). Diabetes mellitus type II was presented in 08 patients (19.04\%), other comorbidities were hypertension in $12(28.5 \%)$, CAD in $09(21.4 \%)$ patients. All patients had pain abdomen while fever and vomiting was presented in $41 \& 38$ pts $(97.6 \%$ \& $90.5 \%)$ respectively. Clinical (vitals parameters, APACHE II score, number of organ system failure and interval between onset of pancreatitis to first PCD placement), haematological and biochemical parameters with morphological characteristics on CECT abdomen were recorded as shown in table 1.

We performed fine needle aspiration of necrosis prior to PCD placement and number of microorganism grown are tabulated in table 2. Patients underwent image guided percutaneous catheter placement. Mean of size of primary catheter, total number and duration shown in table 2. Both PCD placement and laparotomy was associated with complications like bleeding, perforation, fistula formation. Frequency of these complications in both PCD and necrosectomy group is shown in table 2 . Out of 42 patients 08 were already known case of DM. Worsening of diabetes status was evident in $01 \& 04$ patients while new onset seen in total 10 patients $(30.3 \%) ; 02 \& 08$ patients in success and failure group respectively $(\mathrm{p}=0.0373)$. Exocrine deficiency developed in total 11 out of 33 patients $(33.33 \%)$ patients as shown in table 2 . Out of 42 patients $09(30.9 \%)$ responded to PCD only, while 29 patients required necrosectomy in addition to PCD and 09 died. (Fig .1)

Table 1:-Demogrphic, clinical, biochemical \& radiological parameters

\begin{tabular}{|l|l|l|l|}
\hline Variable & Success & Failure & P value \\
\hline Male & 3 & 19 & $\mathbf{0 . 0 1 4}$ \\
\hline Female & 10 & 10 & \\
\hline Age (Mean \pm Sd) & $43.15 \pm 18.06$ & $47.97 \pm 8.09$ & 0.176 \\
Range & $(26-66)$ & $110 \pm 3.72$ & \\
\hline Pulse (Mean \pm Sd) & $106.77 \pm 7.29$ & $66.55 \pm 0.18$ & 0.163 \\
\hline MAP (mm Hg) & $69.92 \pm 0.39$ & $101.32 \pm 1.37$ & $\mathbf{0 . 0 0 1}$ \\
\hline Temp (F) & $101.44 \pm 1.67$ & $24.83 \pm 0.44$ & 0.379 \\
\hline Resp Rate (per Min) & $24.85 \pm 0.98$ & $11.13 \pm 1.08$ & 0.493 \\
\hline Hb (gm \%) & $11.28 \pm 2.06$ & 0.357 \\
\hline
\end{tabular}




\begin{tabular}{|l|l|l|l|}
\hline Lymphocyte & $6.85 \pm 0.5$ & $7.07 \pm 0.24$ & 0.310 \\
\hline S Amylase (U/L) & $469.54 \pm 110$ & $403.59 \pm 137$ & 0.138 \\
\hline Lipase (U/L) & $1263.85 \pm 108$ & $910.52 \pm 98$ & 0.130 \\
\hline Triglyceride (mg/dl) & $132.77 \pm 34$ & $248.55 \pm 68$ & 0.135 \\
\hline S Bil (mg/dl) & $2.13 \pm 1.94$ & $1.99 \pm 1.80$ & 0.381 \\
\hline Sodium (Na) (m Eq/L) & $139.08 \pm 0.45$ & $141.59 \pm 0.56$ & 0.648 \\
\hline Potasium (K) (m Eq/L) & $3.98 \pm 0.48$ & & \\
\hline BUN (mg/dl) & $17.54 \pm 0.80$ & $3.82 \pm 0.42$ & 0.230 \\
\hline Cr (mg/dl) & $1.01 \pm 0.01$ & $18.34 \pm 0.39$ & 0239 \\
\hline Calcium (mg/dl) & $8.15 \pm 0.52$ & $0.86 \pm 0.16$ & 0.137 \\
\hline Sugar (R) mg/dl & $177.38 \pm 56$ & $8.03 \pm 0.57$ & 0.313 \\
\hline Clinical Parameters & & $157.30 \pm 69$ & 0.169 \\
\hline APACHE II & $7.08 \pm 0.54$ & & \\
\hline No of Organ Failure & $0.62 \pm 0.04$ & $9.0 \pm 0.24$ & $\mathbf{0 . 0 1 8}$ \\
\hline $\begin{array}{l}\text { Interval b/w onset to PCD } \\
\text { (Weeks) }\end{array}$ & $5.08 \pm 1.58$ & $1.1 \pm 0.2$ & $\mathbf{0 . 0 2 1}$ \\
\hline Modified CTSI & $5.69 \pm 1.90$ & $4.96 \pm 1.44$ & 0.392 \\
\hline HU & $20.46 \pm 0.65$ & & \\
\hline Vol of Necrosis $(\%)$ & & $7.52 \pm 2.76$ & $<\mathbf{0 0 0 1}$ \\
\hline$<30 \%$ & 05 & & $<\mathbf{0 0 1}$ \\
\hline $0-50 \%$ & 06 & 02 & \\
\hline$>50 \%$ & 02 & 11 & $\mathbf{0 . 0 1 2}$ \\
\hline
\end{tabular}

Table 2:-Number of microorganism Grown, Size, No. \& Duration of Catheter Placed, Complications,

\begin{tabular}{|c|c|c|c|}
\hline \multicolumn{4}{|l|}{$\begin{array}{l}\text { Number of } \\
\text { microorganism Grown }\end{array}$} \\
\hline 0 & 02 & 08 & 0.803 \\
\hline 1 & 05 & 11 & \\
\hline 2 or more & 03 & 10 & \\
\hline \multicolumn{4}{|l|}{$\begin{array}{l}\text { Size, No. \& Duration of } \\
\text { Catheter }\end{array}$} \\
\hline $\begin{array}{l}\text { Size of primary Cather } \\
\text { (Fr) }\end{array}$ & $10.0 \pm 0.53$ & $10.71 \pm 0.25$ & 0.264 \\
\hline $\begin{array}{l}\text { Number of Cather } \\
\text { placed }\end{array}$ & $2.31 \pm 0.9$ & $2.61 \pm 0.84$ & 0.170 \\
\hline $\begin{array}{l}\text { Total Duration of } \\
\text { Cather (Days) }\end{array}$ & $33.23 \pm 10.45$ & $24.59 \pm 11.41$ & 0.121 \\
\hline \multicolumn{4}{|l|}{$\begin{array}{ll}\text { Procedure } & \text { Related } \\
\text { Complications } & \end{array}$} \\
\hline Bleeding & 3 & 5 & 0.476 \\
\hline $\begin{array}{ll}\text { Hollow } & \text { viscus } \\
\text { Perforation } & \end{array}$ & 1 & 3 & 0.316 \\
\hline Pancreatic Fistula & 2 & 5 & 0.239 \\
\hline \multirow[t]{3}{*}{ Diabetes Status } & Already present & 03 & 05 \\
\hline & Worsen & 01 & 04 \\
\hline & New Onset & 02 & $(p=0.037)$ \\
\hline Exocrine Insufficiency & New Onset & 02 & $(\mathrm{P}=0.0228)$ \\
\hline
\end{tabular}




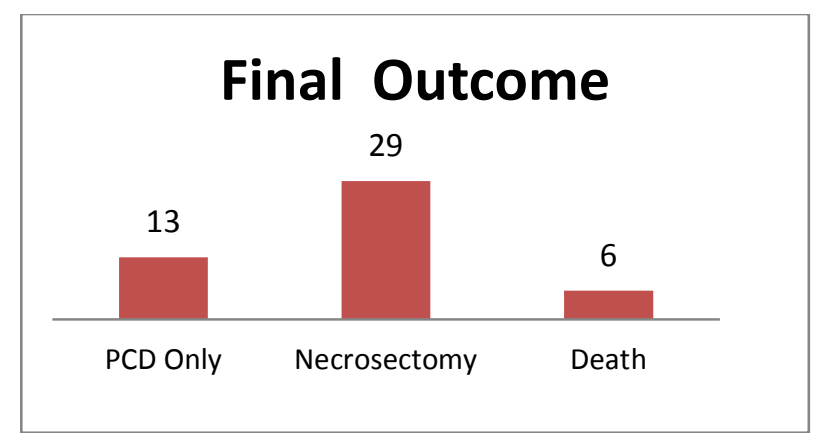

Fig. 1:-Final Outcome

\section{Discussion:-}

Step up approach has been accepted globally by many centres for management of infected necrotizing pancreatitis with varying success reported between 30 to $67 \%$ in available literature [2-5]. Currently little is known about the factors responsible for failure of percutaneous catheter drain. The importance to know about the presence of those predictors in patientis the timely consideration of next step intervention.

In our study age of patient was not associated with percutaneous catheter drain out come while failure to PCD was more in male patients $(78 \%)$ in comparison to females $(50 \%)$. (p value $=0.014)$. In study (Hollemans et al) male sex was found to be one of the predictor of failure percutaneous catheter drainage. This is a one of the largest prospective study in which 22 variables were evaluated in 130 patients underwent catheter drainage and success rate was $35 \%$. [6].

There was no association between age and gender of patients with outcome of percutaneous catheter drainage in studies by Babu RY et al, Guo Q et al, Li A et al [7-9]. Though no clear explanation of this demographic difference, however it is known from the studies in the ICUs that male patients have a higher incidence of severe sepsis, higher level of care and increased need of invasive interventions in comparison of female patients. In present study main etiological factors were cholelithiasis and alcohol consumption. Response to PCD does not affected by etiology in our study ( $\mathrm{p}=0.340$ ). In the studies by Babu RY et al, Holleman et al, Guo $Q$ et al, there was no relationship between etiological factors with response to percutaneous drainage. We could not find any association between hematological parameters and outcome of PCD. In existing literature also there is no such relation has been reported [6-8].

Raised levels of serum amylase and lipase have not been associated with severity of disease as well as response to therapy [10-12]. In our study study no varied response to PCD in patients with raised serum levels of these two enzymes. $(\mathrm{p}=0.798 \& 0.154)$

Low mean arterial pressure (MAP) prior to first intervention was related with increase risk of failure to PCD while other vital parameters (tachycardia, tachypnoea and raised body temperature) were not associated with poor outcome. We observed that high APACHE II score prior to first PCD placement, is associated with more chances of PCD failure $(\mathrm{p}=<0.002)$ and existing literature also support this association. [7]. In this study number of organ failure prior to intervention was one of the predictor associated with negative out come of PCD. $(p=0.021)$ Our results are in line with most of the other studies. [6]. Interval between onset of symptoms and placement of catheter has no relation in our study with PCD out come. $(\mathrm{p}=0.392)$

Morphological characteristic of necrosum; Hounsfield Unit (HU), modified CTSI and volume of necrosis were statistically difference in two groups. Higher HU, modified CTSI and volume of necrosis has negative outcome to PCD.

Equivocal reports available as in studies by Freeny et al, Guillaume b et al, there was no significant difference in the CT severity and outcome, while studies by Hollemanet al, Babu RY et al reported significant association between CT findings of characteristics of collection and PCD outcome $(p=<0.05)[6,7]$. 
Diagnosis of infected necrosis was based either presence of gas in necrosum on CT abdomen or by fine needle aspiration (FNA). In present study there was no association between number of micro organism isolated prior to PCD placement. $(\mathrm{p}=0.803)$.

In our study also there is no statistically significant difference in size, number and total duration of catheter requirement however there is mixed results of various studies. In this study we also analyzed secondary end point which are procedure related complications, status of diabetes mellitus worsening \& new onset, new onset exocrine deficiency and mortality.

In this study procedure related bleeding, hollow viscus perforation and pancreatic fistula in both groups are statically insignificant. ( $p$ values are $0.476,0.316 \& 0.239$ respectively) Our findings are in line with reports of PANTER trial GI bleeding occurred in 7 patients $(16 \%)$ and 10 patients $(22 \%)(p=0.48)$; perforation of a visceral organ in 6 patients $(14 \%) 10$ patients $(22 \%)(p=0.32)$; and pancreatic fistula in $28 \%$ and $33 \%$ patients PCD and necrosectomy groups. ( $p=0.33$ ) In our study diabetes mellitus was developed or worsening of preexisting occurred and exocrine deficiency developed in both groups. However difference was significant in both groups $(p=0.014)$ and $(p=0.036)$. Total death in our study are 09 out of 42 Patients $(20 \%)$, in PANTER trial mortality rate was $17 \%$, while in systemic review by LichiKe et al 104 patients died out of 557 patients (18\%).

\section{Conclusion:-}

To conclude male gender, low MAP, high APACHE II score, number of organ failure prior to intervention and morphology and volume of necrosis on CECT abdomen are the predictors for failure of PCD. Large bore drainage has no added advantage and associated with higher complication rates. Next step intervention in presence of predictors for failure of PCD may be consider early for improve outcome of disease.

The trail has been blazed, traffic is increasing, but the road has yet to be paved. Further work is required, not only in regards to standardizing PCD techniques, but in determining ways to do it better. The challenge is to drive the proportion even higher with more efficient and effective PCD techniques resulting in a decrease in hospital stay and mortality.

\section{References:-}

1. van Santvoort HC, Besselink MG, Bakker OJ, Hofker HS, Boermeester MA, Dejong CH, et al. A step-up approach or open necrosectomy for necrotizing pancreatitis pancreatitis. N Engl J Med 2010; 362:1491-1502

2. Freeny PC, Hauptmann E, Althaus SJ, Traverso LW, Sinanan M. Percutaneous CT-guided catheter drainage of infected acute necrotizing pancreatitis: techniques and results. AJR Am J Roentgenol 1998; 170: 969-975

3. Fotoohi M, D Agostino HB, Wollman B, et al.Persistent pancreatocutaneous fistula after percutaneous drainage of pancreatic fluid collections: role of cause and severity of pancreatitis. Radiology 1999;213:573-8

4. Baril NB, Ralls PW, Wren SM, et al. Does an infected peripancreatic fluid collection or abscess mandate operation? Ann Surg.2000;231:361-7

5. Zerem E, Imamović G, Sušić A, et al. Step-up approach to infected necrotising pancreatitis: a 20 year experience of percutaneous drainage in a single centre. Dig Liver Dis 2011;43:478-83

6. Hollemans RA, Bollen TL, van Brunschot S, et al; Dutch Pancreatitis Study Group. Predicting Success of Catheter Drainage in Infected Necrotizing Pancreatitis. Ann Surg. 2016;263:787-92

7. Babu RY, Gupta R, Kang M , et al. Predictors of surgery in patients with severe acute pancreatitis managed by the step-up approach. Ann Surg. 2013;257:737-50

8. Guo Q, Li A, Hu W. Predictive factors for successful ultrasound-guided percutaneous drainage in necrotizing pancreatitis. Surg Endosc 2016;30:2929-34

9. Li A, Cao F, Li J , et al. Step-up mini-invasive surgery for infected pancreatic necrosis: Results from prospective cohort study. Pancreatology. 2016;ii: 424-3903(16)30007-2

10. W. R. Matull, S. P. Pereira, and J. W. O'Donohue, "Biochemical markers of acute pancreatitis," Journal of Clinical Pathology. 2006;59:340-344

11. P. A. Banks and M. L. Freeman, "Practice guidelines in acute pancreatitis," The American Journal of Gastroenterology. 2006;101:2379-2400

12. V.Keim, N.Teich, F.Fiedler, W.Hartig, G.Thiele, andJ. M ossner,"A comparison of lipase and amylase in the diagnosis of acute pancreatitis in patients with abdominal pain," Pancreas.1998;16:45-49 